\title{
Seasonal Variation Mechanism of Hg in Jiaozhou Bay 1988
}

\author{
Dongfang Yang ${ }^{1,2,3, \text { a , Ming Wang }}{ }^{1,2}$, Xiuzhen Tao ${ }^{1,2}$, Qiang Wang ${ }^{1,2}$, Sixi Zhu ${ }^{1,2}$ \\ ${ }^{1}$ Research Center for Karst Wetland Ecology, Guizhou Minzu University, Guizhou Guiyang, Guizhou \\ Guiyang, China; \\ ${ }^{2}$ College of Chemistry and Environmental Science, Guizhou Minzu University, Shanghai, 550025, China; \\ ${ }^{3}$ North China Sea Environmental Monitoring Center, SOA, Qingdao 266033, China. \\ adfyang_dfyang@126.com
}

Keywords: Mercury (Hg); Seasonal variation; Terrestrial migration; Mechanism; Jiaozhou Bay.

\begin{abstract}
This paper analyzed the vertical distribution and seasonal variation of $\mathrm{Hg}$ in waters in Jiaozhou Bay in 1988. Results showed that Hg contents in surface and bottom waters were in order of spring > summer. In case of Hg contents were relative high/low in surface waters, $\mathrm{Hg}$ contents in bottom waters were also relative high/low. The continuous sediment of $\mathrm{Hg}$ resulted in dilution and accumulation effects in bottom waters. The relative high $\mathrm{Hg}$ contents resulted in dilution effect in bottom waters, while the relative low $\mathrm{Hg}$ contents resulted in accumulation effect in bottom waters. The seasonal variations of $\mathrm{Hg}$ contents in surface waters were determined by the changes of the major $\mathrm{Hg}$ sources, while the corresponding seasonal variations of $\mathrm{Hg}$ contents in bottom waters were results of accumulation effect and dilution effect of waters. The distributions of $\mathrm{Hg}$ contents in surface and bottom waters were reverse in case of the input and sedimentation of $\mathrm{Hg}$ was just beginning, yet were consistent when the input and sedimentation of $\mathrm{Hg}$ had been on-going for a time period. Finally, the mechanism of seasonal variation mechanism and terrestrial migration mechanism were proposed.
\end{abstract}

\section{Introduction}

A large amount of Hg-containing wastes were generated and discharged to the environment along with the rapid development of industry, particularly in the past several decades [1-3]. The terrestrial anthropogenic Hg was discharged to soil, air and waters, and was transported to ocean finally by means of overland runoff, river flow and atmospheric deposition [4-8]. In general, the existence and change of $\mathrm{Hg}$ in marine bay are results of the terrestrial Hg's input and rainfall-runoff, in a large part [19-14]. Hence, understanding the seasonal variation and terrestrial migration mechanism of $\mathrm{Hg}$ is meaningful to pollution control and environmental remediation.

Jiaozhou Bay is a semi-closed bay located in Shandong Province, China. This paper analyzed the vertical distribution and seasonal variation of $\mathrm{Hg}$ in waters in Jiaozhou Bay in 1988, tried to invert the seasonal migration mechanism, and aimed to provide scientific basis for research on the seasonal and spatial changes of $\mathrm{Hg}$.

\section{Study area and data collection}

Jiaozhou Bay is located in the south of Shandong Province, eastern China $\left(35^{\circ} 55^{\prime}-36^{\circ} 18^{\prime} \mathrm{N}\right.$, $\left.120^{\circ} 04^{\prime}-120^{\circ} 23^{\prime} \mathrm{E}\right)$. The total area and average water depth are $446 \mathrm{~km} 2$ and $7 \mathrm{~m}$, respectively. The bay mouth is very narrow $(3 \mathrm{~km})$, and is connected to the Yellow Sea in the south. There are a dozen of rivers including Dagu River, Haibo Rriver, Licun Rriver, and Loushan Rriver etc., all of which are seasonal rivers [15-16].

The investigation on Hg in bottom waters in Jiaozhou Bay was carried on in April and July 1988 in six monitoring sites (i.e., 34, 35, 36, 84, 85 and 90) (Fig. 1). Hg in bottom waters was sampled and monitored follow by National Specification for Marine Monitoring [17]. 


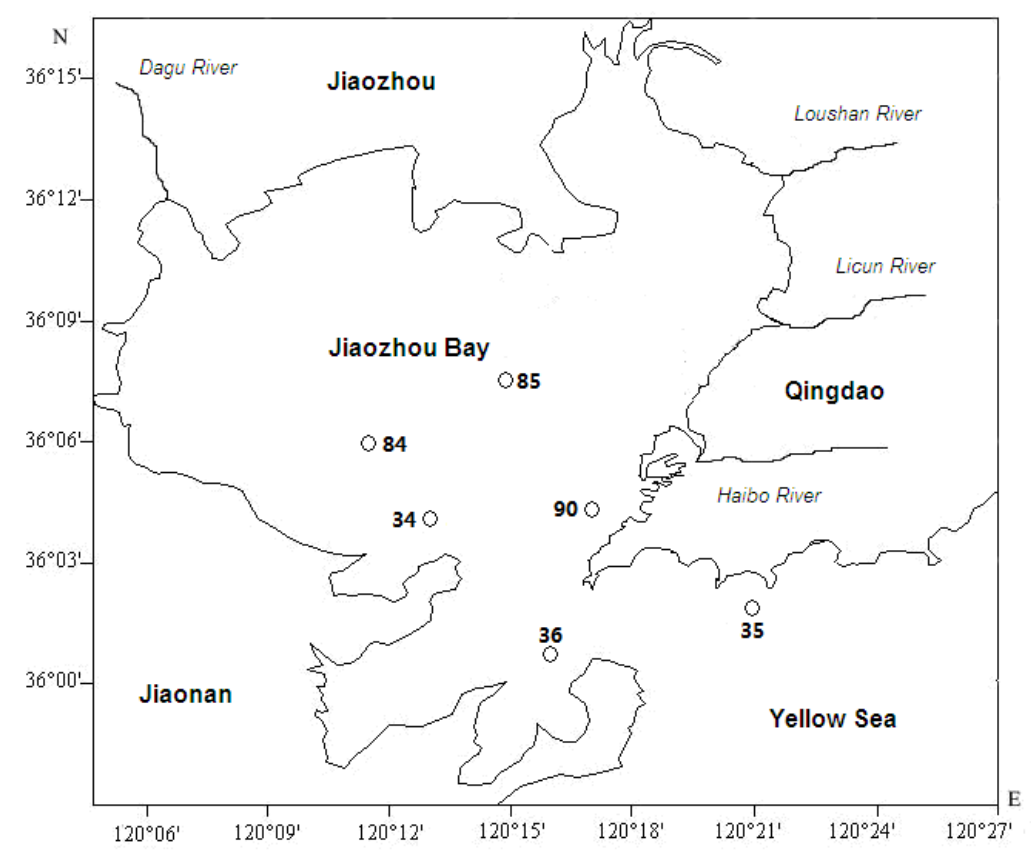

Fig.1 Geographic location and monitoring sites in Jiaozhou Bay

\section{Results}

Hg contents in April 1988 in surface waters and bottom waters were 0.045-0.100 $\mu \mathrm{g}$ L-1 and 0.041-0.128 $\mu \mathrm{g}$ L-1, while in July 1988 were $0.027-0.056 \mu \mathrm{g}$ L-1 and 0.024-0.075 $\mu \mathrm{g}$ L-1, respectively. In according to Guidelines for Hg in Sea Water Quality Standard (GB3097-1997), the pollution level of $\mathrm{Hg}$ in 1988 were ranging from Grade I to Grade II. In general, the pollution levels of Hg in Jiaozhou Bay 1988 was still slight.

April and July were spring and summer in study area, and Hg contents in surface and bottom waters were in order of spring >summer. Meanwhile, it could be found that in case of $\mathrm{Hg}$ contents were relative high/low in surface waters, Hg contents in bottom waters were also relative high/low.

In April 1988, Hg contents in bottom waters were decreasing from Site 34 in the inner side $(0.049 \mu \mathrm{g} \mathrm{L}-1)$ of the bay mouth to Site 35 in the outer side of the bay mouth( $0.045 \mu \mathrm{g} \mathrm{L}-1)$, while in bottom waters were increasing from Site 34 in the inner side $(0.041 \mu \mathrm{g} \mathrm{L}-1)$ of the bay mouth to Site 35 in the outer side of the bay mouth $(0.048 \mu \mathrm{g} \mathrm{L}-1)$.

In July1988, Hg contents in bottom waters were decreasing from Site 34 in the inner side of the bay mouth $(0.033 \mu \mathrm{g} \mathrm{L}-1)$ to Site 35 in the outer side of the bay mouth $(0.027 \mu \mathrm{g} \mathrm{L}-1)$, and in bottom waters were also decreasing from Site 34 in the inner sideof the bay mouth $(0.075 \mu \mathrm{g} \mathrm{L}-1)$ to Site 35 in the outer side of the bay mouth $(0.027 \mu \mathrm{g} \mathrm{L}-1)$. Hence, the horizontal distributions of Hg contents in surface and bottom waters were reverse in April 1988, while in July 1988 were consistent.

\section{Discussion}

Sedimentation process of $\mathrm{Hg}$. Hg contents in waters were changing a lot while transporting through the waters by means of vertical waters's effect [12-14]. The growth and reproduction of marine zooplankton and phytoplankton were increasing from spring to summer [16], resulting a great deal of colloid which was able to enhance the absorption capacity of suspending particular matters. Hence, a big part of Hg was absorbed to the suspending particular matters and transported to sea bottom continuously by means of gravity force and marine current [11]. That was the vertical sedimentation process of $\mathrm{Hg}$. 


\subsection{Seasonal variation of $\mathrm{Hg}$.}

The major Hg sources in spring in Jiaozhou Bay were overland runoff and river flow, whose source strengths were relative strong, and $\mathrm{Hg}$ contents in waters were relative high. The major $\mathrm{Hg}$ source in summer in Jiaozhou Bay were river flow, whose source strengths were relative weak, and $\mathrm{Hg}$ contents in waters were relative low. $\mathrm{Hg}$ contents in surface waters in Jiaozhou Bay were increasing from a relative high level $(0.100 \mu \mathrm{g}$ L-1) in April 1988, and then decreasing and reaching a relative low level $(0.056 \mu \mathrm{g}$ L-1) in July 1988. By means of vertical water's effect and horizontal water's effect [12-14], Hg contents were settling to sea bottom rapidly and continuously. The relative high $\mathrm{Hg}$ contents were diluted when arrived at sea bottom, while the relative low $\mathrm{Hg}$ contents were accumulated when arrived at sea bottom [12-14], resulted in Hg contents in surface and bottom waters were in order of spring >summer. Hence, the sedimentation process of $\mathrm{Hg}$ in waters in April and July 1988 revealed the accumulation effect and dilution effect. The seasonal variations of $\mathrm{Hg}$ contents in surface waters were determined by the changes of the major Hg sources, while the corresponding seasonal variations of $\mathrm{Hg}$ contents in bottom waters were results of accumulation effect and dilution effect of waters.

\subsection{Seasonal variation's mechanism of $\mathbf{H g}$.}

From the point of space, Jiaozhou Bay is a semi-closed bay (Fig. 1), which is surrounded by land in the east, north and west, and is connected with open waters via a narrow bay mouth in the south. $\mathrm{Hg}$ contents in surface waters were decreasing from high value many locations (i.e., estuaries of the major inflow rivers in the west, north and east) to low value in the bay mouth, and were showing the gravity settling of Hg. From the point of season, Hg contents in surface and bottom waters in April and July 1988 were both in order of spring > summer, which were also showing the gravity settling of $\mathrm{Hg}$. For vertical distribution, the horizontal distributions of $\mathrm{Hg}$ contents in surface and bottom waters were consistent in July 1988, indicating that the relative high $\mathrm{Hg}$ contents were extending from the bay to open waters. The horizontal distributions of $\mathrm{Hg}$ contents in surface and bottom waters were confirming the migration process and mechanism in waters [10-11]. Hence, the settling process of $\mathrm{Hg}$ indicated that $\mathrm{Hg}$ was low soluble in waters and could be absorbed to suspending particular matters and transported from surface waters to bottom waters, and fixed to sedimentation in sea bottom finally. The anthropogenic Hg discharged to the environment could be finally transported to waters via water cycle, and to sea bottom finally by means of water's effect.

Once the rainy season has ended, a big part of anthropogenic Hg discharged to air and soil was remained in land surface, and a big part of anthropogenic Hg discharged to rivers was remained in the river bed. There was about a period of six months between the end of the rainy season to the beginning of the rainy season in the flowing year, in where a big part of $\mathrm{Hg}$ was accumulated in land surface and river bed. When the rainy season was coming again in the flowing year, a lot of $\mathrm{Hg}$ was washing from land surface and transporting from river, and was discharging to ocean. Hence, both content and flux of $\mathrm{Hg}$ in April 1988 were highest. As the rainy season was going on, the remaining $\mathrm{Hg}$ in land surface and river bed was decreasing, and the content and flux of $\mathrm{Hg}$ to waters and ocean were also decreasing in summer in July 1988. The seasonal variations of Hg contents in 1988 were consistent with other years during 1979-1986 [1-11], that was Hg contents in surface waters weer relative high in spring, and were relative low in summer, and were lowest in autumn. That was the seasonal variation's mechanism of $\mathrm{Hg}$, and was also the terrestrial migration mechanism.

\subsection{Spatial distribution's mechanism of $\mathbf{H g}$.}

The input of Hg to Jiaozhou Bay in April 1988 was relative high, and the horizontal distributions of $\mathrm{Hg}$ contents in surface and bottom waters were reverse. Hg contents in surface waters were decreasing from the inner side of the bay mouth to the outer side of the bay mouth in April 1988, and a big part of $\mathrm{Hg}$ was settling rapidly to bottom waters by means of gravity and current. However, the relative high $\mathrm{Hg}$ contents were just arriving at the bay mouth, in where the sedimentation of $\mathrm{Hg}$ was just beginning. Hence, $\mathrm{Hg}$ contents in bottom waters in the inner side of 
the bay mouth were still relative low, resulted in a increasing trend from the inner side of the bay mouth to the outer side of the bay mouth. That was the reason of the horizontal distributions of $\mathrm{Hg}$ in surface and bottom waters were reverse in April 1988.

The input of Hg to Jiaozhou Bay in July 1988 was relative low, and the horizontal distributions of $\mathrm{Hg}$ contents in surface and bottom waters were consistent. Hg contents in surface waters were also decreasing from the inner side of the bay mouth to the outer side of the bay mouth in July 1988, and a big part of Hg was settling rapidly to bottom waters by means of gravity and current. Since the sedimentation of $\mathrm{Hg}$ was on-going from spring to summer, a lot of $\mathrm{Hg}$ was accumulating in the inner side of the bay moth, resulted in a decreasing trend from the inner side of the bay mouth to the outer side of the bay mouth. That was the reason of the horizontal distributions of $\mathrm{Hg}$ in surface and bottom waters were consistent in July 1988.

In general, the distributions of $\mathrm{Hg}$ contents in surface and bottom waters were reverse in case of the input and sedimentation of $\mathrm{Hg}$ was just beginning, yet were consistent when the input and sedimentation of $\mathrm{Hg}$ had been on-going for a time period.

\section{Conclusion}

$\mathrm{Hg}$ contents in surface and bottom waters were in order of spring >summer. In case of $\mathrm{Hg}$ contents were relative high/low in surface waters, $\mathrm{Hg}$ contents in bottom waters were also relative high/low. The continuous sediment of $\mathrm{Hg}$ resulted in dilution and accumulation effects in bottom waters. The relative high $\mathrm{Hg}$ contents resulted in dilution effect in bottom waters, while the relative low $\mathrm{Hg}$ contents resulted in accumulation effect in bottom waters.The seasonal variations of $\mathrm{Hg}$ contents in surface waters were determined by the changes of the major $\mathrm{Hg}$ sources, while the corresponding seasonal variations of $\mathrm{Hg}$ contents in bottom waters were results of accumulation effect and dilution effect of waters.The distributions of $\mathrm{Hg}$ contents in surface and bottom waters were reverse in case of the input and sedimentation of $\mathrm{Hg}$ was just beginning, yet were consistent when the input and sedimentation of $\mathrm{Hg}$ had been on-going for a time period.

There was about a period of six months between the end of the rainy season to the beginning of the rainy season in the flowing year, in where a big part of $\mathrm{Hg}$ was accumulated in land surface and river bed. When the rainy season was coming again in the flowing year, a lot of Hg was washing from land surface and transporting from river, and was discharging to ocean. As the rainy season was going on, the remaining $\mathrm{Hg}$ in land surface and river bed was decreasing, and the content and flux of $\mathrm{Hg}$ to waters and ocean were also decreasing. Hence, $\mathrm{Hg}$ contents in surface waters weer relative high in spring, and were relative low in summer, and were lowest in autumn. That was the seasonal variation's mechanism of $\mathrm{Hg}$, and was also the terrestrial migration mechanism.

\section{Acknowledgment}

This research was sponsored by the China National Natural Science Foundation (31560107), Doctoral Degree Construction Library of Guizhou Nationalities University and Research Projects of Guizhou Nationalities University ([2014]02), Research Projects of Guizhou Province Ministry of Education (KY [2014] 266), Research Projects of Guizhou Province Ministry of Science and Technology (LH [2014] 7376).

\section{References}

[1] Chen Y, Gao ZH, Qu YH, et al.: Chinese Journal of Oceanology Limnology, Vol. 25(2007), p. 455-458. (in Chinese)

[2] Yang DF, Cao HR, Gao ZH, et al.: Ocean Environmental Science, Vol. 27 (2008), p. 37-39.

[3] Yang DF, Wang LL, Gao ZH, et al.: Ocean Environmental Science, Vol. 28 (2009), p. 501505 .

[4] Chen Y, Zhang YJ, Gao JH, et al.: Ocean Development and Management, Vol. 30 (2013), p. 
81-83.

[5] Yang DF, Sun PY, Ju L, et al: Coastal Engineering, Vol. 32(2013), p.65-76.(in Chinese)

[6] Yang DF, Xu ZJ Qu YF, et al.:Coastal Engineering, Vol. 33(2014), p. 67-78.(in Chinese)

[7] Chen Y, Qu YF, Pei RL, et al.:Advanced Materials Research, Vol.955-959 (2014), p. 2491-2495.

[8] Yang DF, Zhu SX, Wang FY, et al.:Advanced Materials Research, Vol.955-959(2014), p. 2496-2500.

[9] Yang DF, Zhu SX, Wang FY, et al.: Applied Mechanics and Materials, Vol.556-562 (2014), p. 633-636.

[10] Yang DF, Wang FY, He HZ, et al.: Advanced Materials Research, Vols.955-959(2014),p. 1443-1447.

[11] Yang DF, Geng X, Qu YF, et al.: Ocean Development and Management, Vol. 31 (2014), p. 112-118. (in Chinese)

[12] Yang DF, Wang FY, He HZ, et al.: Proceedings of the 2015 international symposium on computers and informatics, 2015, p. 2655-2660.

[13] Yang DF, Wang FY, Zhao XL, et al.: Sustainable Energy and Enviroment Protection, Vol. 2015, 191-195.

[14] Yang DF, Wang FY, Yang XQ, et al.:Advances in Computer Science Research, Vol. 2352 (2015), p.198-204.

[15] Yang DF, Chen Y, Gao ZH, et al.: Chinese Journal of Oceanology and Limnology, Vol. 23(2005), p. 72-90. (in Chinese)

[16] Yang DF, Wang F, Gao ZH, et al. Marine Science, Vol. 28 (2004), p. 71-74. (in Chinese)

[17] China's State Oceanic Administration: The specification for marine monitoring (Ocean Press, Beijiang 1991), p.1-300. (in Chinese) 